NBER WORKING PAPER SERIES

DIGITAL CURRENCIES, DECENTRALIZED LEDGERS, AND THE FUTURE OF
CENTRAL BANKING

Max Raskin

David Yermack

Working Paper 22238

http://www.nber.org/papers/w22238

\author{
NATIONAL BUREAU OF ECONOMIC RESEARCH \\ 1050 Massachusetts Avenue \\ Cambridge, MA 02138 \\ May 2016
}

The authors thank Daniel Alter, Michael McConnell and Geoffrey Miller for helpful comments. Part of this research was completed while Yermack was a visiting professor at Erasmus University Rotterdam. The views expressed herein are those of the authors and do not necessarily reflect the views of the National Bureau of Economic Research.

NBER working papers are circulated for discussion and comment purposes. They have not been peer-reviewed or been subject to the review by the NBER Board of Directors that accompanies official NBER publications.

(C) 2016 by Max Raskin and David Yermack. All rights reserved. Short sections of text, not to exceed two paragraphs, may be quoted without explicit permission provided that full credit, including $(\odot$ notice, is given to the source. 
Digital Currencies, Decentralized Ledgers, and the Future of Central Banking

Max Raskin and David Yermack

NBER Working Paper No. 22238

May 2016

JEL No. E42,E51,E52,E58,G21

\begin{abstract}
$\underline{\text { ABSTRACT }}$
Central banking in an age of digital currencies is a fast-developing topic in monetary economics. Algorithmic digital currencies such as bitcoin appear to be viable competitors to central bank fiat currency, and their presence in the marketplace may pressure central banks to pursue tighter monetary policy. More interestingly, the blockchain technology behind digital currencies has the potential to improve central banks' payment and clearing operations, and possibly to serve as a platform from which central banks might launch their own digital currencies. A sovereign digital currency could have profound implications for the banking system, narrowing the relationship between citizens and central banks and removing the need for the public to keep deposits in fractional reserve commercial banks. Debates over the wisdom of these policies have led to a revival of interest in classical monetary economics.
\end{abstract}

\author{
Max Raskin \\ New York University School of Law \\ New York, NY 10012 \\ maxraskin@nyu.edu \\ David Yermack \\ Stern School of Business \\ New York University \\ 44 West Fourth Street, Suite 9-160 \\ New York, NY 10012 \\ and NBER \\ dyermack@stern.nyu.edu
}




\section{Digital currencies, decentralized ledgers, and the future of central banking}

\section{Introduction}

Digital currencies were created to compete with central banks.

Nakamoto’s (2008) design of bitcoin, as a “Peer to Peer Electronic Cash System,” was intended to allow network members to transfer value directly between each other without any role for a trusted third party, such as a central bank. Few people noticed the launch of bitcoin in early 2009, but its creator, still unknown today, had a clear political agenda. The first block of bitcoins was accompanied by the encoded text, “The Times 03/Jan/2009 Chancellor on brink of second bailout for banks.” Appearing near the lowest depths of the global financial crisis, this headline from The Times provided an implicit commentary on the fragility of the world banking system and the inability of central banks to do anything about it. Bitcoin's anonymous creators symbolically hard-coded this message into the "genesis block" of their main innovation, the blockchain. They could hardly have expected that within five years, their blockchain and its shared ledger would be viewed as major breakthroughs in financial record-keeping, with central banks, stock exchanges, and numerous other financial markets beginning to co-opt the disruptive technology in order to modernize their own operations.

This chapter evaluates the challenges and opportunities for central banks in a world that appears to have been irreversibly changed by the arrival of algorithmic digital currencies. The world economy had been moving away from hard currency in favor of electronic payment systems for many years before the arrival of bitcoin. Such an innovation was not unexpected, with prominent economists of past generations such as John Nash (2002) and Milton Friedman speaking openly of the opportunities for an algorithmic currency, issued according to a mathematically fixed policy rule, to usurp the role of central banks and discretionary monetary 
policy. ${ }^{1}$ Yet bitcoin represented a radical departure from past schemes, with a novel focus on decentralized governance and record-keeping that placed control of money in the hands of its users, rather than a committee of elected politicians or a circle of enlightened experts. The equations underlying bitcoin stipulated a predetermined and transparent rate of monetary growth, pre-empting the use of discretionary monetary policy that might debase the currency in response to an economic slump.

At the time of this writing, bitcoin faces a significant governance issue, as its community of users has been unable to reach consensus about how to scale its network to accommodate rapid growth in transaction volume. Ironically, the lack of political leadership that seemed so important in the design of bitcoin is an obstacle in settling on a strategy for the currency to grow. Even as the bitcoin network struggles with delays and bottlenecks, blockchains and distributed ledger innovations have been incorporated by hundreds of knock-off imitator digital currencies. These innovations have also inspired financiers, regulators, and academics to reconsider the first principles of central banking, including whether central banks should reinvent their national currencies in algorithmic form, residing on national blockchains and shared ledgers overseen by the very institutions that bitcoin's creators wished to do away with.

Central banking in an age of digital currencies is a fast-developing topic in monetary economics. Algorithmic digital currencies such as bitcoin appear to be viable competitors to central bank fiat currency, and their presence in the marketplace may pressure central banks to pursue tighter monetary policy. However, the technology behind digital currencies may be coopted by central banks themselves, giving them more power and greater control over monetary policy than ever before. This chapter provides a brief introduction to these topics, with the caveat that the field is changing so quickly that new issues and opportunities seem likely to reshape the research agenda frequently. Section II provides a brief overview of the structure of bitcoin and alternative digital currencies. Section III considers how central banks have reacted to competition from alternative currencies, outside the official national monetary base. Section IV discusses implications of the possibility that central banks may issue their own digital currencies

\footnotetext{
${ }^{1}$ See Babbage (2011), which provides a concise introduction to the structure of bitcoin and begins by recounting Friedman's oft-repeated calls for replacing the U.S. Federal Reserve System with an automated rule for money creation. In a videotaped 1999 interview that has been widely shared on the Internet, Friedman seemed to anticipate the arrival of bitcoin ten years later when he stated, "I think that the Internet is going to be one of the major forces for reducing the role of government ... The one thing that's missing, but that will soon be developed, is a reliable ecash, a method whereby on the Internet you can transfer funds from A to B, without A knowing B or B knowing A.”
} 
with blockchain and distributed ledger architecture. Section V provides an overview of operational benefits that may accrue to central banks from incorporating the new technology into their processing systems, even if they choose not to issue digital currency. Section VI concludes the chapter.

\section{Emergence of digital currencies}

Digital currencies that circulate today confound some members of the public who question the value of an asset that exists only in computer memory. However, the idea of virtual money is not new, as electronic payment systems have steadily grown with advances in computer memory and communications technology, inexorably supplanting hard currency and paper checks in advanced economies. The distinguishing features of digital currencies really come from their independence from any political authority or commercial sponsor as well as their decentralized governance and record-keeping.

Various forms of electronic money have circulated for decades. Twenty years ago, both the Office of the U.S. Comptroller of the Currency (1996) and the Bank for International Settlements (1996) published reports noting the proliferation of "electronic cash" stored on "smart" debit cards that consumers could use at a point of sale. These devices differed in two important ways from the digital currencies circulating today: they were always denominated in units of a sovereign currency, such as the U.S. dollar, and their stored value was created via a transfer of value from a third party, typically a credit card issuer such as MasterCard or Visa. Early concerns about the growth of electronic cash focused on computer security issues and the solvency of the third party guarantors.

Online fantasy games provided a platform for issuing virtual currencies beginning in the late 1980s, and today many regard these as predecessors of bitcoin and other autonomous digital currencies. These massively multiplayer online role-playing games, or MMORPGs, have internal economies in which players earn rewards in the fantasy currency and spend them to acquire in-game powers or objects from other players. Some of these currency markets have become deep enough that they have migrated to external platforms, where they trade on a speculative basis against real-world currencies (Kim, 2015). Promoters of these games need to consider issues such as seignorage and inflation of the monetary base much like a central bank would. 
To some observers, the first private digital currency to establish itself as a medium of exchange in the real economy was M-Pesa, a currency denominated in mobile phone minutes that was launched in Kenya by Safaricom in 2007. M-Pesa could be acquired by anyone with a mobile phone and could be transferred over great distances at extremely low cost. Within two years, it had been used by more than half the population of Kenya (Jack and Suri, 2011). Kaminska (2015) observes that M-Pesa appears to have succeeded because Safaricom, which is $40 \%$ owned by the multinational giant Vodaphone, is trusted by the public more than the Kenyan banking system, but she argues that M-Pesa really resembles a money transmission service more than a standalone currency, since its sponsor collateralizes units of M-Pesa with Kenyan hard currency deposits in escrow accounts. The reach of M-Pesa does not appear to have extended beyond the Kenyan economy, although parallel mobile phone based currency systems have been introduced in other developing nations.

Bitcoin, proposed in an Internet posting by Nakamoto (2008) and introduced into circulation in 2009, probably has a more clear-cut claim to being the first successful private digital currency, as it is used in countries all around the world and is not tied to any established banking system as is the case with M-Pesa. Bitcoins are circulated over an open computer network that can be joined by anyone with an Internet connection. Users of the network store bitcoins in computer memory banks colloquially known as digital wallets, and transfers occur via an encryption system described in Babbage (2011) and numerous other sources. Bitcoins can be acquired in the stream of commerce (by exchanging goods and services for bitcoins) or as a reward for participating in "mining," the activity by which users update the network's "blockchain," or archive of previous bitcoin transactions. Bitcoins paid out as mining fees represent the seigniorage of new currency, which occurs at a fixed rate that periodically ratchets downward until it is scheduled to asymptotically approach no new money creation in 2140.

Bitcoin features a number of innovations in security, seigniorage, and transparency that appear to have contributed to its success. Its archival blockchain links together all previous transfers of a given unit of currency as a method of authentication. The blockchain is known as a "shared ledger" or "distributed ledger," because it is available to all members of the network, any one of whom can see all previous transactions into or out of other digital wallets. Perhaps most importantly, the process of reaching "consensus" to validate transactions on a bitcoin network requires no trusted third party, such as a central bank, credit card issuer, or mobile phone 
company, to play the role of authenticator. Instead, authentication relies upon an algorithmic proof-of-work process that enables users to trust one another with very high levels of confidence, removing the need for sponsor to play the role of enforcer or gatekeeper on the network. This feature reduces the central bank to a set of equations in the bitcoin economy.

Bitcoin’s success has spawned hundreds of imitator digital currencies, which are generally distinguished from one another by differences in their protocols for mining and proof of work. Although bitcoin continues to have by far the largest market capitalization, successful competitor digital currencies have included litecoin, ripple, and most recently, the ether currency that ciculates on the Ethereum platform. ${ }^{2}$

\section{Central banks and competition from digital currencies}

When an autonomous digital currency circulates in an economy, it competes with the official currency issued by the country's central bank. Competition between official currency and private money is nothing new, and in various societies alternative money has included commodities like gold and silver as well as other goods that have served as stores of value and media of exchange. However, in most countries the local currency faces its greatest competition from foreign governments’ currencies, especially the U.S. dollar. For a central bank, the challenges posed by a digital currency are basically the same as those posed by the presence of a competing foreign currency.

For an economy, competition among currencies causes suppliers to drive price and quality to an appropriate equilibrium that reflects utility (Hayek, 1976). Historically, most of these suppliers have been central banks, although there are numerous and well-documented examples of non-central bank currency used both idiosyncratically and generally (Radford, 1945). One benefit from competition between different monies is the stability produced by the flexibility of contracting parties to choose settlement terms. Private creditors and debtors, if given a free choice, will tend to use the currency that is neutral as between them. Debtors would not want to contract in currencies that would appreciate after contracting, and creditors would not want to contract in currencies that would depreciate. Thus, from the point of view of consumers of money, having competitors in the provision of money is a check on the unilateral

\footnotetext{
${ }^{2}$ More than 700 digital currencies have been launched since the inception of bitcoin, and a list with current market values is maintained at http://coinmarketcap.com/all/views/all/.
} 
behavior of the supplier. Put into concrete terms, digital currencies could offer a country struggling with a mismanaged money supply a way of creating stability.

Argentina provides an instructive recent example of how digital currencies, like foreign currencies, have the ability to provide a check against a central bank's policy rules that are detrimental to a country. According to the World Bank, Argentina has experienced double-digit inflation every year except one since 2002. ${ }^{3}$ Such a situation wrecks havoc on a country's economy by adding unwanted risk to capital allocation decisions. Before the 2015 election of President Mauricio Macri, The New York Times reported on the use of bitcoin in evading the country's currency controls amid an atmosphere of financial instability (Popper, 2015). When the Argentine peso and the country's central bank were unable to provide individuals with the qualities they demanded of their money, they were relatively free to switch to other options, which included not only digital currencies but also the U.S. dollar and other foreign currencies. A country which risks its participation in global financial markets if its currency is too unstable will be more likely to tolerate the use of black and grey market options. ${ }^{4}$ Prior to becoming president, Macri served as mayor of Buenos Aires, where he helped organize a bitcoin forum. After being inaugurated, one of his first actions was to lift the country's currency controls.

A slightly different approach was adopted by Ecuador, which officially banned bitcoin in 2014, but introduced its own digital currency project called Sistema de Dinero Electrónico (electronic money system) (Rosenfeld, 2015). Modeled on private providers of mobile money, the system gives individuals access to mobile credit accounts denominated in currency approved by the central bank. Ecuador's official currency is the U.S. dollar, which it adopted after years of monetary instability. As articulated by the Ecuadorian government, the new digital system is not designed to replace the dollar, but to save money on replacing deteriorating physical bills. Some, however, have seen the project as a move towards de-dollarization and an attempt by the government to assert more control over the economy (White, 2014). ${ }^{5}$ Certainly the banning of

\footnotetext{
${ }^{3}$ http://data.worldbank.org/indicator/NY.GDP.DEFL.KD.ZG/countries/AR?display=default.

${ }^{4}$ Iran provides another recent example. See Raskin (2012).

${ }^{5}$ As White writes, "In sum, there is no plausibly efficient or honorable reason for the Ecuadoran government to go into the business of providing an exclusive medium for mobile payments. Consequently it is hard to make any sense of the project other than as fiscal maneuver that paves the way toward official de-dollarization. I gather that President Correa does not like the way that dollarization limits his government's power to manage the economy.”
} 
bitcoin and other digital currencies demonstrates that the advantages of competition are not what the Banco Central del Ecuador envisioned in establishing the new system.

With the above benefits in mind, we now turn to the costs of competing digital currencies, which primarily consist in undermining a central bank's ability to conduct monetary policy as a monopolist. In a world where central banks are forced to compete with other central banks and private actors, supply and demand alone will drive which money is used as the generally accepted medium of exchange. However, central banks operate under regimes that have enacted legal tender laws whose function is to compel acceptance of their notes. ${ }^{6}$ Such laws do not require parties to contract in the currency of the central bank, but they deny legal recourse to a party who refuses to accept the legal tender of the country as payment for debts contracted in some other medium of exchange. This gives rise to Gresham's Law, namely that bad money drives out the good. ${ }^{7}$ At the same exchange rate, a debtor is less likely, ceterus paribus, to pay in appreciated currency if he has the option to pay in depreciated currency.

Legal tender laws therefore confer a monopoly privilege on the government, allowing it to operate its printing press. Without such laws, central banks would simply be banks. If consumers were allowed to refuse acceptance of central bank currency for public and private debts, a regime of free banking would exist and the central bank would be forced to operate monetary policy in accord with the demands of its consumers and not according to political or policy goals untethered from the market. Whether the central bank's monopoly power is desirable is beyond the scope of this chapter and is part of an enduring "rules vs. discretion" debate in macroeconomics.

The history of American monetary policy provides an important example. Until the 1861-65 U.S. Civil War, currency in the United States was issued by private banks, including the First Bank of the United States, which, though chartered by Congress was still a private institution. In order to fund the Civil War without raising taxes, Congress passed the Legal Tender Act in 1862, which authorized the issuance of \$150 million in United States notes, which were declared to be "lawful money and legal tender in payment of all debts, public and private, within the United States, except duties on imports and interest on the public debt.” This

\footnotetext{
${ }^{6}$ See, e.g., 31 U.S.C §5103 (United States); Coinage Act 1971 §2 (United Kingdom); Reserve Bank Act 1959 §36(1) (Australia); Bank of Israel Law 1954 §30 (Israel).

${ }^{7}$ Mundell (1998) states that "The correct expression of Gresham's Law law is: 'cheap money drives out dear, if they exchange for the same price.' That proposition is neither trivial nor obvious.”
} 
legislation was politically controversial and was at first declared unconstitutional by the U.S. Supreme Court. Writing for the Court on behalf of a 4-3 majority in Hepburn v. Griswold, Chief Justice Salmon P. Chase held that forcing parties to accept depreciated currency violated the Constitution's prohibition against governmental taking of property without due process of law. The Chief Justice found no distinction between the Legal Tender Act "and an act compelling all citizens to accept, in satisfaction of all contracts for money, half or three-quarters or any other proportion less than the whole of the value actually due, according to their terms. It is difficult to conceive what act would take private property without process of law if such an act would not."8

The Hepburn decision was reversed the next year in a pair of 5-4 decisions that were supported by two new Justices who, coincidentally, were appointed by President Grant on the same day that Hepburn was decided. ${ }^{9}$ Together these two decisions are known as the Legal Tender Cases, and few in the American legal scene today advocate their reversal. ${ }^{10}$ The U.S. has reached a political consensus that the federal government should not operate without a legal safety net that privileges its currency.

These events in $19^{\text {th }}$ century United States history provide an interesting context for understanding the 2014 political debate in Iceland. That country confronted an alternative to its króna in the form of a private, autonomous digital currency called auroracoin that was targeted squarely at the Icelandic market. Introduced by the pseudonymous Baldur Friggjar Óðinsson, auroracoin entered circulation in March 2014 by way of an “airdrop” in which 50\% of auroracoins were distributed evenly to holders of Iceland's Kennitala national identification. These events occurred when Iceland was operating under strict capital controls in the aftermath of the global financial crisis, which had decimated the country’s banking system. The

\footnotetext{
${ }^{8}$ Hepburn v. Griswold, 75 U.S. 603 (1870). Ironically, Chase had served as President Lincoln's Secretary of the Treasury and had played a role in enacting the Legal Tender Act in 1862.

${ }^{9}$ Knox v. Lee and Parker v. Davis, 79 U.S. 457 (1871).

${ }^{10}$ See Bork (1987) who at his Supreme Court confirmation hearings testified, "I cite to you the legal tender cases. Scholarship suggests - these are extreme examples, admittedly - scholarship suggests that the framers intended to prohibit paper money. Any judge who today thought he would go back to the original intent really ought to be accompanied by a guardian rather than be sitting on a bench.” But see Epstein (2014), who writes, "As a matter of constitutional principle, therefore, Legal Tender laws should fall by the wayside, thereby preserving both the rule of law and the stability of private expectations... One way to counteract this risk [of arbitrary power to inflate or deflate] is to let the government print whatever (cheap) currency it will, but to discipline its behavior by allowing other banks to issue their own currency (whether or not backed by gold) in competition with the federal government."
} 
introduction of auroracoin prompted the government to hold a parliamentary meeting of the Economic Affairs and Trade Committee. Frosti Sigurjónsson, chairman of the committee, wrote, "There is evidence however that this is a case of [a money] scam and illegal," but the government ultimately took no action against it (Cawrey, 2014). By all accounts, auroracoin has been a failure and has not supplanted the Icelandic króna in any meaningful way.

Along with legal tender laws, governments can use licensing requirements for money transmission to regulate indirectly the threat from competing currencies. These laws make it easier for governments to combat tax evasion and money laundering, which have been widely reported uses of digital currencies such as bitcoin.

Countries have taken different attitudes towards digital currencies, ranging from equivocating or hostile to laissez-faire and encouraging. Often an overlap exists between these attitudes and how the country treats foreign currencies generally. For instance, in China the government imposes capital controls, combined with active market intervention by the central bank, to affect the value of the renminbi, demonstrating a policy choice that disfavors private actors setting the values of foreign exchange rates. Similarly, the country's attitude towards bitcoin and other digital currencies also ties the hands of private actors. Although it is legal for individuals to own bitcoin in China, banks and financial institutions are prohibited from doing so. In April of 2014, the People's Bank of China ordered commercial banks and trading companies to shut down accounts that dealt in bitcoin. In addition to concern about the financial well-being of their citizenry, the Chinese government may see bitcoin and other digital currencies as a threat to the country's capital controls, given the ease of transmitting bitcoin across international borders.

The United Kingdom, on the other hand, allows the private use of bitcoin as well as the opening of businesses that transact in the currency. Many officials in the United States government have expressed a similar attitude of benign neglect toward digital currencies (Raskin, 2013). ${ }^{11}$ Although anti-money laundering laws apply in both countries, neither has attempted to ban bitcoin or prevent its proliferation. Indeed, Andrew Haldane, the Bank of

\footnotetext{
${ }^{11}$ While the U.S. has tolerated the circulation of private digital currencies and other instruments such as the Ithaca Hour (which takes its value from the price of an hour of labor), the government's forebearance does not extend to private coinage incorporating precious metals. The United States in 2009 prosecuted the issuer of Liberty Dollars, a private currency pegged to the market prices of gold and silver. Liberty Dollars had shapes and denominations similar to the official U.S. coinage but featured portraits of Congressman Ron Paul, a political libertarian.
} 
England's Chief Economist, has suggested that digital currencies might be a solution to the supposed zero lower bound problem of monetary policy, as we discuss in Section IV below. The U.S. Library of Congress provides a comprehensive analysis of bitcoin's treatment in various jurisdictions. $^{12}$

\section{Should central banks issue their own digital currencies?}

Although bitcoin and other digital currencies were created to bypass the control of central banks, the possibility of a central bank withdrawing its bills and notes from circulation and replacing them with its own digital currency has become an appealing topic of debate among monetary economists. This would result in omnipotent uber-banks such as the U.S. Federal Reserve co-opting the very technology that was created to compete against them.

Koning (2014), in a blog post titled "Fedcoin," has advanced the most trenchant and widely discussed proposal for a central bank digital currency, although his work draws on a number of earlier, similar proposals by others. The Fedcoin ideas have been taken up and discussed by two top officials of the Bank of England, Haldane (2015) and Broadbent (2016), in recent public speeches, leading to some speculation that the U.K. might be the first country to launch a national digital currency. If a digital pound did enter the marketplace, it would almost certainly have to circulate alongside traditional coins and banknotes, at least for a time, to accommodate citizens who were uncomfortable with modern technology as well as those who were unable to afford ordinary consumer devices such as mobile phones.

Under the Fedcoin proposal, citizens and businesses would be permitted to open accounts at the central bank itself, rather than depositing their funds in commercial banks as is done today. Central banks historically have not taken deposits from the public, because the sheer volume of required record-keeping and customer contact would be overwhelming (Winkler, 2015). Digital technology overcomes these concerns, since cloud-based servers and storage could easily accommodate very large volumes of financial transactions, and bank branches and ATMs would not have to be maintained if currency could be accessed via mobile phones and other hand-held electronics. Central bank digital accounts could initially be funded by permitting depositors to convert existing currency, presumably at a 1-to-1 rate, and the new digital currency would reside on a blockchain operated by the central bank. When depositors wished to spend their digital

\footnotetext{
${ }^{12}$ See http://www.loc.gov/law/help/bitcoin-survey/
} 
currency, they would transfer it over the blockchain to the account of a counterparty, with the central bank coding each transaction into its blockchain. Rather than being updated by miners in competition with one another, the blockchain would instead be overseen by a trusted third party - the central bank - which would have the exclusive right to add or modify entries. In addition, a central bank's blockchain would almost certainly be kept hidden, at least to an extent, in order to preserve the privacy of citizens and the competitive secrets of businesses. Because of these two differences, a central bank’s blockchain would be markedly different than the open, shared ledger that is characteristic of digital currencies that operate by consensus of the network members and do not rely on a powerful gatekeeper. It has led some to question whether a central bank blockchain would be a blockchain at all. Such centralization would also represent a single point of failure that could make the entire financial system vulnerable to hacking or sabotage.

By concentrating deposits in the central bank, Fedcoin schemes would implicitly end the practice of fractional reserve banking, thereby "narrowing” the banking system so that depositors dealt directly with the central bank rather than with intermediary private banks. In many ways, Fedcoin represents a revival of the 1933 “Chicago Plan,” a widely discussed academic proposal to end fractional reserve banking in order to restore public confidence during the Great Depression.

Monetary policy would become much easier for the central bank to implement under a digital currency system. The bank could commit to an algorithmic rate of money creation and control it precisely via interest on customer deposits. In principle, this interest rate could be negative. Such a policy could be modified by contingent smart contracts that could change the rate of money creation if the economy followed certain future paths. Alternatively, the central bank could retain discretion to adjust the money supply on a tactical basis as part of a stabilization policy. In either case, the concept of open market operations would by superseded by direct manipulation of customer balances, which could be targeted finely toward certain geographical regions or distinct demographic or economic clienteles of depositors. Broadly speaking, this narrowing of the banking system to a direct relationship between citizens and the central bank would represent financial socialism. The implications of this innovation would be vast, and below we sketch some of its potential benefits and costs.

Allowing private accounts at the central bank would solve many problems inherent in the current fractional reserve banking system. The central bank would not be vulnerable to bank 
runs, and governments could exit the business of providing deposit insurance and occasional bailouts as the lender of last resort to inadequately funded commercial banks. Commercial banks would no longer have to engage in "maturity transformation," under which they raise funds from short-term demand deposits and lend them out in long-term mortgages and other loans. Riskshifting and other moral hazard problems on the part of banks, which now receive free deposit insurance from the government, might be eliminated.

In macroeconomics, the main advantages to a central bank of having its own digital currency would come from giving the government more control and understanding of the financial system. Such control would permit better intervention in response to the business cycle while also ensuring better individual compliance with tax collection and anti-money laundering statutes.

As articulated by Haldane (2015), a central bank digital currency could solve the "zero lower bound" problem by permitting the central bank to reduce interest rates below zero as a strategy to encourage spending and investment. When money circulates in the form of bills and notes, negative interest rates can be difficult to implement because citizens can hoard hard currency, obtaining an interest rate of zero, and refuse to deposit it into banks which would confiscate some fraction of it under a negative interest rate regime. Haldane notes that for much of the $20^{\text {th }}$ century, relatively high real interest rates around the world made the zero lower bound problem all but irrelevant. However, a sustained drop in real interest rates in recent years has made the problem potentially important again. This has occurred for a variety of reasons, including the economic slump during the global financial crisis and changing demographic patterns that affect savings patterns in advanced economies.

If the main innovation of digital currency is to permit the central bank to force interest rates below zero, the public might come to resent the technology or even prevent its introduction. In 2013, the "bail-in" recapitalization of banks in Cyprus proved politically controversial and difficult to implement, after the government proposed that banks increase their equity by reducing the balances in certain customer accounts. A negative interest payment by a bank to its depositors would mean much the same thing, and citizens might have difficulty seeing the broad public benefits of an interest rate policy that led the government to erase some of their cash from computer memory. The Cypriot Financial Crisis fueled a massive increase in the price of bitcoin, seeing the currency rise to its current all-time high of $\$ 1216.73$ per bitcoin. 
If a central bank digital currency did narrow the banking system by transferring the deposit-taking function away from commercial banks and into the hands of the central bank, the dangers to the commercial banking sector could be severe. Commercial banks would lose access to their main source of funds and would either have to cut back on lending or raise new capital by issuing securities to investors. The new financing would probably be far more costly and less stable than demand deposits. As a result, commercial banks might greatly reduce their lending activity to both businesses and private citizens, such as for mortgage loans or commercial lines of credit. It is not clear how the economy might compensate to offset the effects of this likely credit contraction. Perhaps, however, the abolition of mandatory fractional reserve banking would smooth out the business cycle if done through private reforms. See von Mises (1912).

A related problem would likely arise in the regulatory sphere. A central bank that took deposits from the public would end up competing head to head with commercial banks, even as it served as the regulatory overseer of the same institutions.

Such a socialization of banking is not without its critics. A central bank controlling and tracking a national digital currency would have immense power to observe and potentially to control an individual's finances. The government could determine how much currency each individual owned and on what and where he spent his money, without the need for any independent judiciary to subpoena the information. Many people prefer to hold hard currency for precisely this reason. If governments issued digital currency, a political clientele would very likely emerge out of concern that digital currency would create a dangerous temptation for abuse. Additionally, although the cost of creating physical currency is not a total check on the government's ability to devalue a currency, without having to print dollars or mint coins, a central bank would be able to hyperinflate in a costless manner simply by adding more zeros to accounts.

Though free banking, like a free economy, is more difficult to control and understand than a centrally planned economy, modern economics has come to the conclusion that through the channeling of incentives, well-defined property rights, and profit calculation, such disorganization produces a more robust and productive system. 


\section{Central bank operations using blockchains}

Central banks may never elect to narrow the banking system and issue digital currency along the lines of the Fedcoin model. However, like other financial institutions central banks may see great appeal in the blockchain technology that lies at the foundation of bitcoin and other algorithmic currencies, and central banks may choose to adapt blockchains for use in their payments processing and transaction clearing functions. Even though the original goal of digital currency blockchains was to facilitate peer-to-peer value transfers that could bypass the interbank clearing process, the technology may ironically find its widest use in allowing central banks to move money more reliably and more cheaply between their depositors. The central bank currency would be a settlement currency, akin to the function served by gold in the past.

Banks perform these bookkeeping and settlement tasks not only for themselves, but also on behalf of commercial banks. Although blockchain technology remains in its infancy, estimates of its potential savings in processing and bookkeeping costs often fall in the range of $50 \%$ to $80 \%$. For a central bank processing enormous volumes of transactions, ${ }^{13}$ the possible size of these savings is substantial.

When central banks oversee payment and settlement functions on behalf of the entire financial system, they seek to provide a system that is both safe and efficient in order to create a high level of public confidence in the health of the banking system. See Bank for International Settlements (2005). Central banks process transactions on behalf of businesses, consumers, banks, and international counterparts, and even small gains in efficiency can save vast amounts of money. Despite the potential to achieve efficiencies through economies of scale, certain segments of the money transfer market such as international remittances remain extraordinarily costly for users. According to the World Bank, at the end of 2015 the average cost of an international money transfer was $7.37 \%$ worldwide, and it was only modestly lower, at $6.89 \%$, for sending funds overseas from one of the G8 countries. ${ }^{14}$ Such transfers typically take several

\footnotetext{
${ }^{13}$ As an example, The U.S. Federal Reserve's FedWire electronic transfer service has handled an average daily volume of \$3 trillion since November 2013, and the Fed operates several other payment and clearing services such as the Automated Clearinghouse (ACH) system. Fedwire statistics are available at https://www.frbservices.org/operations/fedwire/fedwire_funds_services_statistics.html.

${ }^{14}$ See https://remittanceprices.worldbank.org/sites/default/files/rpw_report_december_2015.pdf.
} 
days to complete due to many layers of checking and verification in the clearing process. ${ }^{15}$ In addition, fraud and theft remain problems, even when the parties involved are government central banks. ${ }^{16}$ While the international money transfer market involves numerous intermediaries in addition to central banks, blockchain technology could make many of them unnecessary. It would have the beneficial side effect of allowing central banks to monitor the behavior of their depositors more directly, helping to defeat problems such as money laundering and tax evasion.

\section{Conclusions}

Digital currencies present central banks with challenges and opportunities. In some economies, bitcoin has emerged as viable competition for fiat currencies during periods when the central bank is perceived as weak or untrustworthy, although to date these cases remain limited to troubled economies with capital controls. More interestingly, the blockchain technology behind digital currencies has the potential to improve central banks’ payment and clearing operations, and possibly to serve as a platform from which central banks might launch their own digital currencies. A sovereign digital currency could have profound implications for the banking system, narrowing the relationship between citizens and central banks and removing the need for the public to keep deposits in fractional reserve commercial banks. This could lead to a serious de-funding of the commercial banking sector and have spillover effects into credit creation and monetary policy. Debates over the wisdom of these policies have led to a revival of interest in classical monetary economics. Competition among fiat currency and private digital currency evokes the $19^{\text {th }}$ century “free banking” era, while the possibility for central banks to issue digital currency recalls the 1930s Chicago Plan for narrowing the financial system by eliminating fractional reserve banking.

As a disruptive new technology, digital currency forces governments and central banks to choose between banning, tolerating, or co-opting its innovations. In most mature economies, central banks have taken the middle course, with a few openly examining the possibility of

\footnotetext{
${ }^{15}$ Perhaps, however, both the monetary and time cost of international remittance is a designed feature of the system to ensure compliance with national policies designed to combat ills like terrorism and sex trafficking.

${ }^{16}$ In a widely reported recent case, the government of Bangladesh lost \$81 million in March 2016 when thieves operating through Philippine banks obtained access codes that enabled them to purloin the funds from Bangladesh's account at the Federal Reserve Bank of New York (Whaley and Gough, 2016).
} 
incorporating sovereign digital currencies into their operations. With so much still to be learned about the possibilities of digital currencies and blockchains, a central bank digital currency still appears to be a radical proposition that carries significant risks for the rest of the financial system. Moreover, a mandatory central bank digital currency with the protection of legal tender laws would stand athwart the vision of competition, decentralization, and openness that the creators of modern digital currencies envisioned. 


\section{References}

Babbage, 2011, “Virtual Currency: Bits and Bob,” The Economist, June 13.

Bank for International Settlements, 1996, “Implications for Central Banks of the Development of Electronic Money,” available at http://www.bis.org/publ/bisp01.pdf.

Bank for International Settlements, 2005, “Central Bank Oversight of Payment and Settlement Systems,” available at http://www.bis.org/cpmi/publ/d68.htm.

Bork, Robert H., 1987, “Excerpts From Questioning of Judge Bork by Senate Committee Chairman,” The New York Times, September 16.

Broadbent, Ben, 2016, “Central Banks and Digital Currencies,” available at http://www.bankofengland.co.uk/publications/Documents/speeches/2016/speech886.pdf.

Cawrey, Daniel, 2014, “Icelandic Parliament Committee Holds Closed Session to Discuss Auroracoin,” Coindesk, March 14, available at http://www.coindesk.com/icelandic-parliament-committee-holds-closed-session-discussauroracoin/.

Epstein, Richard A., 2014, The Classical Liberal Constitution: The Uncertain Quest for Limited Government, Harvard University Press.

Haldane, Andrew G., 2015, “How Low Can You Go?” available at http://www.bankofengland.co.uk/publications/Documents/speeches/2015/speech840.pdf.

Hayek, Friedrich A., 1976, Denationalisation of Money: The Argument Refined, Institute of Economic Affairs.

Jack, William, and Tavneet Suri, 2011, “Mobile Money: The Economics of M-Pesa,” National Bureau of Economic Research working paper 16721.

Kaminska, Izabella, 2015, “Mpesa: The Costs of Evolving an Independent Central Bank,” Financial Times, July 15.

Kim, Thomas, 2015, “The Predecessors of Bitcoin and Their Implications for the Prospect of Virtual Currencies,” PLoS ONE 10(4): e0123071.

doi:10.1371/journal.pone.0123071.

Konig, J.P., 2014, “Fedcoin,” available at http://jpkoning.blogspot.com/2014/10/fedcoin.html.

Mundell, Robert , 1998, “Uses and Abuses of Gresham’s Law in the History of Money,” Zagreb Journal of Economics 2, no. 2, 3-38. 
Nakamoto, Satoshi, 2008, “Bitcoin: A Peer to Peer Electronic Cash System,” available at https://bitcoin.org/bitcoin.pdf.

Nash, John F. Jr., 2002, "Ideal Money," Southern Economic Journal 69, 4-11.

Office of the Comptroller of the Currency, 1996, “An Introduction to Electronic Money Issues,” unpublished manuscript, available at http://www.occ.gov/topics/bank-operations/bit/intro-to-electronic-money-issues.pdf.

Popper, Nathaniel, 2015, “Can Bitcoin Conquer Argentina?” The New York Times, April 29.

Radford, Robert A., 1945, “The Economic Organisation of a P.O.W. Camp,” Economica, New Series 12, no. 48, 189-201.

Raskin, Max, 2012, “Dollar-Less Iranians Discover Virtual Currency,” Bloomberg News, November 29.

Raskin, Max, 2013, “U.S. Agencies to Say Bitcoins Offer Legitimate Benefits,” Bloomberg News, November 18.

Rosenfeld, Everett, 2015, “Ecuador becomes the first country to roll out its own digital cash,” CNBC, February 9.

von Mises, Ludwig, 1912, The Theory of Money and Credit.

Whaley Floyd, and Neil Gough, 2016, “Brazen Heist of Millions Puts Focus on Philippines,” The New York Times, March 16.

White, Lawrence H., 2014, "Dollarization and Free Choice in Currency,” George Mason University Department of Economics Working Paper, No. 14-44.

Winkler, Robin, 2015, “Fedcoin: How Banks Can Survive Blockchains,” Konzept 6, 6-7. 